\title{
Information Sharing and the Dimensions of Social Capital in Second Life
}

Journal of Information Science $1-12$

(C) The Author(s) 2013

Reprints and permissions: sagepub.co.uk/journalsPermissions.nav DOI: I0.II77/0I6555I5I0000000 jis.sagepub.com

\section{Isto Huvila}

Department of ALM, Uppsala University, Sweden

Information Studies, School of Business and Economics, Åbo Akademi University, Finland

\section{Stefan Ek}

Information Studies, Faculty of Humanities, University of Oulu

\section{Gunilla Widén}

Information Studies, School of Business and Economics, Åbo Akademi University, Finland

\begin{abstract}
Earlier research has shown that the virtual world of Second Life is an environment, which fosters the emergence of social capital. The central finding of this study is the pertinence of emotional communication and information sharing in the emergence of social capital in SL, and consequently, the significance of emotional intelligence as a basis for successful social and informational exchange. The emergence of social capital in Second Life is deeply affected by the dialectic of the conflicting expectations and experiences of the environment. The emergence of social capital in Second Life may be described as a process of accumulation of emotional intelligence that forms a basis for the exploitation of available structural and relational affordances of social and information exchange. The study is based on qualitative analysis of open-ended data collected using a web survey of Second Life users.
\end{abstract}

\section{Keywords}

Information sharing, social capital, virtual worlds, Second Life

\section{Introduction}

Second Life (SL) is an online virtual world. It is a social venue for work, learning, education, entertainment and cooperation that reflects the activities and interests of its users (residents in SL terminology)[1]. The residents, rather than the company that maintains and develops the virtual world, have created the most of the content and are responsible for the activities taking place in the virtual world [2]. SL is a place where people with shared interests can meet, be and work together. It is a place where communities can emerge on the basis of these shared interests [1].

Earlier research has shown that socialising is a major reason for participating in SL and that SL is an environment, which fosters the emergence of social capital [3]. At the same time, the earlier studies on information sharing and socialising in virtual worlds have suggested that these environments have several specific affordances and constraints not found in other types of digital environments. For instance, the multi-modality of communication (e.g. [4]) and possibility to interact with a three-dimensional environment [5] has been suggested to enhance social exchange [6] and consequently, processes of information use [7] and learning [8]. The accumulation of social capital is, however, a complex process. The present study discusses findings from an empirical study in SL looking closer at the subtleties of social capital and how it is linked to information sharing. Data $(\mathrm{N}=67)$ for the study was gathered using a web survey. The conception of social capital of this study is principally based on Bourdieu [9] and Putnam [10]. The analysis of the functioning and dimensions of social capital is based on the notion of the three dimensions of social capital introduced

\section{Corresponding author:}

Isto Huvila, Information Studies, School of Business and Economics, Åbo Akademi University, Fänriksgatan 3B, 20500 Åbo, Finland firstname.lastname@abo.fi 
by Nahapiet and Ghoshal [11] and how they are linked to information sharing according to the model of Widén-Wulff et al [12]. Finally, the study borrows the notions of affordance and constraint from the ecological approach of Gibson [13].

The aim of this study is to examine the dynamics how the characteristics and functionality of SL are linked to the dimensions of social capital and what types of affordances and constraints they set for information sharing; i.e., what is the role of social capital in SL and in SL information sharing in particular.

\section{Literature review}

\section{I. Social capital and virtual worlds}

Social capital is built from the social relationship that an individual has and that gives access to the resources of these relationships, and the amount and quality of these resources [9]. Social capital as a resource is integrated in the people a person is connected to and the access to social capital is based on an expected reciprocity in a relationship when the donor expects to receive some return on their investment or through solidarity that derives from ones identification in some group. This could lead to positive outcomes such as access to information or more effective sharing of information. Seen as a purely individual resource, it is about getting help and support from other people, e.g. for solving problems, catching opportunities or accomplishing relevant goals [14]. Putnam [10] brought another viewpoint to the research of social capital when he defined social capital as "features of social organizations, such as networks, norms, and trust that facilitate action and cooperation for mutual benefit."

When studying social capital, different dimensions have been introduced in order to better map its benefits and outcomes [11]. The aim of the categorisation is to describe the social environment through structural, relational, and content dimensions, and to underline how these different dimensions support knowledge development and the achievement of personal and professional goals [12]. Network structures and the nature of the network ties can help actors to reach different kinds of benefits and goals. Social interactions in the structures function as channels for information flows. The underlying motives for sharing are stressed in the relational dimension. Trust is an important enabler to both motivating and using social technologies [15]. This is challenging in online environments because trust is usually built over a relatively long period of time [16]. The structural and relational dimensions are cornerstones for gaining social opportunities to develop shared meaning and collective knowledge, that is the content dimension of social capital [12].

The mechanisms of how social capital works in a virtual environment are not always straightforward. Social capital has been studied in many kinds of virtual communities, such as virtual learning communities [17,18] and social networking sites [19]. According to Blanchard and Horan [20] social capital can increase in virtual communities that are based on existing physical communities. Putnam [21], whose extensive research showed a decline of social capital in the United States during the last decades of the 20th century, argues that the Internet may work to an opposite direction. According to Lin [22] "we are witnessing a revolutionary rise of social capital, as represented by cyber-networks."

Coleman [23] discusses social capital from a family and community point of view and underlines the need to substitute the earlier formal society with a voluntary and spontaneous social organisation, which can provide people with the social capital they need. This has been underlined through many of the success stories on the Web, e.g. Wikipedia, which are based on volunteerism and user created content. The same applies for SL, as everything from buildings to social groups and from vehicles to experiences is created by the users. In a study of players of the multiplayer online game World of Warcraft, it was shown that players formed different kinds of social networks in the game where rules, boundaries, and norms were formed [24]. The fact that SL incorporates elements that can be described as playful and game-like make comparisons between SL and online games useful. At the same time, even if some authors claim that SL is a "game", its open-ended nature, lack of pre-written narrative and the relative lack of game-like rules that constrain interactions in ther virtual world (in contrast to more everyday life like constraints) suggest that direct analogies between games and SL should be made cautiously.

The research conducted so far shows that social capital can emerge in virtual communities and more specifically, in virtual worlds, but further research is needed to get a clearer understanding of the phenomenon. The majority of earlier research has focussed on communities with a given frame of reference whether it is topic of interest or fantasy game, instead of new open-ended user-created virtual worlds with a clear emphasis on socialising like SL that have increased in popularity in recent years.

When discussing the development of social capital and its effects on information sharing it is relevant also to look into different intelligences underlying these processes. The notion of social capital is closely connected to social intelligence. There is no consensus of the definition of the concept. On the basis of the literature review of Salovey and 
Mayer [25] it is possible to conclude that social intelligence is about understanding people and understanding personality. Social intelligence is an ability to manage people, relations and different types of social contexts.

Social intelligence consists of several subsets of intelligences. Emotional intelligence is a significant aspect of social intelligence that involves "the ability to monitor one's own and others' feelings and emotions, to discriminate among them and to use this information to guide one's thinking and actions." [25]. This means that emotional intelligence focuses one's emotional states as well as others', individually or in groups, supporting problem solving and regulating behaviour [25].

The emotional aspect has been studied in connection to social capital in organizations and, for instance, Brooks \& Nafukho [26] have looked into the relationship between social capital, emotional intelligence and human resource development. Their findings underline that emotional intelligence is a basis for social capital and that social capital shapes the opportunities to develop human resources and organizational performance. Organizations strive to engage employees who have high emotional intelligence, and advanced cognitive skills. These abilities contribute to the developing of social capital, and consequently, result in innovativeness and creativity [26,27].

The emotional perspective appears particularly relevant in the context of information activities and social capital in SL. Riva et al. [28] have showed that virtual environments function as an affective media. Their affective nature has been explained by several factors including the sense of presence [28] and the playful and game-like characteristics of the environments [29, 30]. Emotional intelligence is put into play especially when an activity demands high levels of personal commitment and interpersonal trust. Füllbrunn et al. [31] found in an experiment that people trusted each other less in SL than outside of the virtual world, even if at the same time in SL, people behaved significantly more trustworthy than outside. Different kinds of emotions arise when people engage in collective action, especially in a new environment. Emotions like anxiety, fear and conflict of values arise as well as feelings of success and joy [27]. Social influence and motives like emotions affect one's intensions to use social software [32]. Engaging in a virtual world demands both commitment and trust which at the same time are the main challenges in the context of studying information sharing and development of the relational dimension of social capital.

\subsection{Information sharing in virtual worlds}

People use multiple and multi-faceted strategies to find information in virtual worlds [7]. Besides purely task-oriented purposes, such as information seeking and sharing for problem solving, the people who visit virtual communities may as well go there for support, friendship and a sense of belongingness, i.e. for emotional information sharing [33,34]. Emotion communication has briefly been defined "as the recognition, expression and sharing of emotions or moods between two or more individuals" [35]. In fact, Barnes and Pressey [36] found that arousal, pleasure and individualism were particularly significant attributes for individuals to meet their goals in virtual environments. In a recent study by Webber [37] we can see that positive emotions are also connected to information encountering and e.g. enthusiasm is experienced when information is found. It is thus important to realize that individuals are clearly aiming at satisfying perceived real world needs, much of emotional origin, through their participation in virtual world settings [36]. McKenna and Bargh [38] point out that one apparent benefit of interacting and information sharing in virtual environments is that it may offer opportunities to people to try out new personality traits that they would ideally like to possess. Furthermore, virtual settings provide a useful interacting tool for those who are socially shy and reclusive to express themselves without any physically face-to-face constraints [38].

Information sharing in virtual communities has also been proved a two-sided coin of calculation and enjoyment, as individuals contribute to virtual networks due to both purely goal-oriented, egoistic motives (e.g., they perceive it enhances their professional reputation) and altruistic motives (they simply like to help others without any hidden agenda) [39]. Virtual environments are, on the other hand, tempting places to behave in an uninhibited way, i.e. to display negative emotions, frustrations and aggressions [40]. The relative anonymity, as well as the relative absence of developed social norms, or any kind of social control, makes virtual encounters convenient for bullying and other forms of abusive and disruptive behaviour [35,41]. For some people, virtual environments may simply be perceived as safer contexts, especially for the communication of negative emotions and inappropriate behaviours [42].

Although emotions, feelings and moods are intrinsic and fundamental properties of human beings, which influence both cognition, perception and behaviour $[43,44]$, there has been relatively little research on the affective dimension of human information behaviour and use within the LIS field. The research of Kuhlthau constitutes the very notable exception. In her studies of users' perspectives of the information seeking process she explicitly observed the significance of the affective aspects, along with the cognitive and physical aspects, of information behaviour and meaning construction $[45,46,47]$. In the slipstream of Kuhlthau's pioneering work other empirical studies, conducted in 
various contexts, have also found that emotion is a substantial component for understanding human information behaviour $[48,49,50]$. Concerning computer-mediated virtual environments like SL, a certain emotional outcome may furthermore well occur, namely device-induced frustration and anxiety, attributed to technical shortcomings (bugs, systems freezing or crashing, time consuming etc.) [51,52,53].

In LIS research, information behaviour has traditionally been studied with the focus on people's work tasks and within educational settings, or in terms of what could be called major life events, i.e. the research approach has mainly been explicitly instrumental. Thus, until recently there has been virtually nothing on information behaviour in leisure pursuits [54], and for most people joining and participating in SL are, at least in the beginning, a pure leisure activity. In the literature, it seems to be an implicit assumption that the meaning of leisure grows out of paid work $[55,56,57,58]$. According to Csikszentmihalyi [55] the opposite may likewise be true, though, when he argues that the most basic meaning of professional and other instrumental activities could as well be determined by reference to meanings developed in leisure settings rather than vice-versa. This is an important remark with regard to a primarily leisure activity like SL hence information sharing and meaning construction in SC add, at best, a bonus world of meaningful information and knowledge to the real one, where the professional life takes place.

This blend of real and virtual life contexts have been underlined in several studies focusing on SL as a learning environment $[59,60,37]$ where SL is seen as a novel and rich information ground with benefits connected to information needs, seeking and use and where new tools and learning techniques are identified on the basis of their accessibility, flexibility, and interactivity. New tools in SL also introduce new ways of thinking about real world information interactions. Webber [37] has explicitly studied how applicable information behaviour models derived from contexts outside SL can be applied to the SL environment. She could clearly identify the information seeking stages proposed by Ellis [61] such as browsing, monitoring, and purposive search. Most of the information in SL is encountered according to Erdelez [62] model of information encountering. Webber [37] shows a very broad picture of information behaviour in SL and proposes a blended model of information behaviour where effective use of a variety of channels, sources, and techniques are underlined, and where people are moving between digital and offline contexts.

\section{Material and methods}

The data was gathered using a web survey. The respondents form a convenience sample $(\mathrm{N}=67)$ recruited using email invitations posted on slrl@list.academ-X.com and educators@secondlife.com mailing lists, personally to Finnish SL users, personally recruiting informants from randomly chosen areas in SL and using instant messages sent within SL to personal contacts of the authors.

The full questionnaire consisted of a set of 74 questions. The present article focuses on the part of the questionnaire that consisted five open ended questions (negative and positive experience in SL, earning in SL, activities, general observations) and 11 questions about demographics (age, gender, income level, housing and living, language, education) and SL usage (hours per week, duration of membership, type of SL account, SL gender). The questions are partially based on earlier surveys on social capital by Bullen and Onyx [63] and Nood and Attema [64], and SL use by NMC and EDUCAUSE [65] and Holmberg and Huvila [66,67]. A quantitative analysis of the remaining material has been published earlier in [3].

Following the premises of qualitative web surveys [68], the answers to the open-ended questions were analysed qualitatively using the constant comparative method [69] and close reading [70] of the utterances expressed by the respondents. The model of the three dimensions of social capital (relational, structural and content) of Nahapiet and Ghoshal [11] was used as a frame of reference in the categorisation. The initial analysis was conducted by one and reviewed independently by three researchers. Finally, a negative case analysis [71] was conducted to increase the validity of the coding.

The presence of the three dimensions of social capital of Nahapiet and Ghoshal [11] could be discerned clearly in the analysis of the answers. The Table 1 contains a summary of the analysis with positive and negative factors of the dimensions of social capital. 
Table I. Dimensions of social capital in Second Life (SL) ( $n=$ mentions).

\begin{tabular}{|c|c|c|c|c|c|}
\hline \multicolumn{2}{|c|}{ Relational $(n=66)$} & \multicolumn{2}{|c|}{ Structural $(n=33)$} & \multicolumn{2}{|c|}{ Content $(n=32)$} \\
\hline$+(n=29)$ & $-(n=37)$ & $+(n=17)$ & $-(n=16)$ & $+(n=30)$ & $-(n=2)$ \\
\hline For roleplaying (2) & $\begin{array}{l}\text { Griefing, bullying } \\
\text { (I3) }\end{array}$ & Global network (7) & $\begin{array}{l}\text { Takes too much } \\
\text { time (I) }\end{array}$ & Expertise (I) & Frustration (I) \\
\hline $\begin{array}{l}\text { Meeting new } \\
\text { friends (7) }\end{array}$ & $\begin{array}{l}\text { (Relationships } \\
\text { with) suspicious } \\
\text { motives (6) }\end{array}$ & $\begin{array}{l}\text { Conference, } \\
\text { symposium (5) }\end{array}$ & Few people (2) & $\begin{array}{l}\text { Learning outcomes } \\
\text { (3) }\end{array}$ & Lost time $(\mathrm{I})$ \\
\hline $\begin{array}{l}\text { Meeting new } \\
\text { relations ( } 2 \text { ) }\end{array}$ & Dishonesty (I) & $\begin{array}{l}\mathrm{RL} \text { and } \mathrm{SL} \\
\text { connected } \\
\text { (meeting } \mathrm{RL} \text { people } \\
\text { in } \mathrm{SL} \text { and } \mathrm{RL} \text { ) (I) }\end{array}$ & $\begin{array}{l}\text { Avatar } \\
\text { management (I) }\end{array}$ & Exchanging ideas (I) & \\
\hline $\begin{array}{l}\text { Meeting } \\
\text { friendly/supportive/ } \\
\text { helpful people (7) }\end{array}$ & $\begin{array}{l}\text { Violence, } \\
\text { aggression (5) }\end{array}$ & $\begin{array}{l}\text { Environment for } \\
\text { setting up a } \\
\text { meeting place(I) }\end{array}$ & $\begin{array}{l}\text { Search problems } \\
\text { (I) }\end{array}$ & Best practices (I) & \\
\hline $\begin{array}{l}\text { Meeting RL friends } \\
\text { (2) }\end{array}$ & $\begin{array}{l}\text { Abusive behaviour } \\
\text { (2) }\end{array}$ & $\begin{array}{l}\text { Venue for meeting } \\
\text { people ( } 2 \text { ) }\end{array}$ & Lag (I) & Tutoring (I) & \\
\hline $\begin{array}{l}\text { Meeting people } \\
\text { known from other } \\
\text { soc media (I) }\end{array}$ & Addictive (I) & $\begin{array}{l}\text { (Educational i.e. } \\
\text { topic specific) } \\
\text { Network (I) }\end{array}$ & Tech problems (5) & $\begin{array}{l}\text { Education/teaching } \\
\text { (2) }\end{array}$ & \\
\hline $\begin{array}{l}\text { Meeting old friends } \\
\text { (I) }\end{array}$ & $\begin{array}{l}\text { People with bad } \\
\text { values ( } 2)\end{array}$ & & $\begin{array}{l}\text { Navigational } \\
\text { problems (I) }\end{array}$ & $\begin{array}{l}\text { Meeting compatible } \\
\text { people (3) }\end{array}$ & \\
\hline $\begin{array}{l}\text { Meeting new } \\
\text { people (3) }\end{array}$ & Mistrust (I) & & Bad interface (3) & Excitement (I) & \\
\hline $\begin{array}{l}\text { Helping people to } \\
\text { connect/meeting } \\
\text { people (I) }\end{array}$ & $\begin{array}{l}\text { Humanities bad } \\
\text { side also in SL (I) }\end{array}$ & & $\begin{array}{l}\text { Difficult functions } \\
\text { (I) }\end{array}$ & Meeting friends $(\mathrm{I})$ & \\
\hline $\begin{array}{l}\text { Meeting interesting } \\
\text { people (I) }\end{array}$ & Stalking (I) & & & Free items (I) & \\
\hline $\begin{array}{l}\text { Stimulating sex } \\
\text { encounters (I) }\end{array}$ & $\begin{array}{l}\text { RL stigma } \\
\text { associated with } \\
\text { online relations ( } \mathrm{I})\end{array}$ & & & CoP (same goals) (6) & \\
\hline \multirow[t]{3}{*}{$\begin{array}{l}\text { Doing things with } \\
\text { friends }(I)\end{array}$} & $\begin{array}{l}\text { Immature } \\
\text { behaviour (I) }\end{array}$ & & & Exhibition (I) & \\
\hline & Sexual assault (I) & & & $\begin{array}{l}\text { Research, testing, } \\
\text { learning }(8)\end{array}$ & \\
\hline & $\begin{array}{l}\text { Relationship } \\
\text { problems (I) }\end{array}$ & & & & \\
\hline
\end{tabular}

\section{Analysis}

The presence of the three dimensions of social capital of Nahapiet and Ghoshal [11] could be discerned clearly in the analysis of the answers. The Table 1 contains a summary of the analysis with positive and negative factors of the dimensions of social capital with the number of occurences of each factor in the material given in parentheses.

The structural dimension is present in that SL functions as a global channel for communication and a framework for general and topic specific activity. A respondent described as a positive experience "[m]eeting people I have interacted with via other distant means - online groups, videoconference - in a convenient and affordable way." (R63). Multiple respondents described SL also as an aesthetically pleasing environment: "the world created is often aesthetically pleasing" (R62) and that there are "nice places/sites around the world" (R29). SL provides residents also with an infrastructure of tools for socialisation and information exchange that the respondents considered as useful (e.g., R34). SL is a 'place', or a "permanent location" according to respondent R19, where activity takes place and the respondents made a clear distinction from the activity outside SL, or in Real Life (RL) (e.g., R28). The world itself contains a further level of locality. Themed 'sims' (simulators) i.e. areas (e.g., R2, 34, R41) and places like bars, offices (R29), museums (R22), galleries (R58), sandboxes (R19) are "places" or "sites" (R29) within SL. The virtual world offers similarly a 
framework for coordination and timing by imposing a synchronous environment with a common reference time (Pacific Time, UTC-7/8). SL functions equally as a frame of reference in a broader scale. The most frequently mentioned positive aspect of structural dimension is the globality ( 7 specific mentions, see Table 1) of the network leveraged by SL (e.g. R1, R2, R24, R48). There are emerging patterns how to solve problems with trust and relationships and conflicts. Further, SL offers a framework for social organisation in form of groups, inworld events and meetings (5 mentions on for instance "conference" or "symposium", and 3 on "venue" or "environment" for meeting people/setting up a meeting place, see Table 1). Respondents mentioned events such as classes (R52), art gallery openings (R58), supporting communities (R28), tours, activities (e.g. scuba diving) (R4), business meetings (R48), demonstrations, live music events, product release parties (R72) and roleplay sessions (e.g., R5, R17).

In addition, the economic system provides a structural element for interactions in SL. Money is a structural enabler for both economic and social exchange. With money, it is possible to construct meeting places (R29), purchase virtual commodities like clothing (R75) and jewellery (R71) and, for instance, to use services offered by other residents (R35). In addition, the economic system provides a framework for activities in SL. Searching for freebies (free items) (e.g., R15, R60) and earning money by, for instance, building (e.g., R40, R49), camping (e.g., R5, R25) or participating surveys (e.g., R10, R22) structure activity in the virtual world. At the same time, the existence of paid premium accounts and the possibility to purchase Linden Dollars (an internal SL currency) using a real credit card creates a point of convergence between RL and SL. There seems to be a clear difference between three predominant modes of economic participation and non-participation by those who primarily earn their Linden Dollars in SL, those who rely on their premium account stipend and those without income or expenses.

Even if SL was portrayed as primarily enabling infrastructure, respondents complained about technical problems (5 specific mentions), slowness (lag in SL terminology), and the difficulty of navigating, searching and using the client software (altogether 8 complaints, e.g. "bad interface", "avatar management", see Table 1). Individual respondents reacted also to the small number of people (2) they had met in SL and the fact that SL use takes too much time (1). Altogether, the positive (17) and negative (16) responses concerning the structural dimension of social capital in SL were close to even (see Table 1).

The relational dimension of social capital can be seen in the opportunities for social interactions, trust relations and occasions when assumed trust has been broken, self-identification to mainstream and marginal groups and communities and by the closure created by the otherness of the virtual world from the real life experiences and surroundings of the users. Multiple respondents described how SL enables them to meet new people ( 7 responses on e.g. "meeting new friends" and 2 on "meeting new relations", see Table 1), old friends and people they know (or are aware of) from other contexts, making friends and building relationships (7 responses emphasized "meeting friendly/supportive/helpful people"). Many respondents expressed their appreciation of the friendliness and the behaviour of other residents by stating, for instance, that "[p]eople have been friendly" and "VERY decent" (R56). Respondent R19 compared SL to other types of virtual environments and hailed the peer-interaction in SL as something unique.

It appears that the participation in SL is very much a question of identities. Some residents choose to mix their real life identities with their SL identities (e.g., R2, R50) while other residents are very clear about the difference of the two or more (if one person has different avatars, e.g. for work and time off, e.g., R23) different identities. One respondent described how she consciously altered the external identity of the avatar by changing her avatar to be less attractive so that she would feel safer (R55). The most typical way of identifying with an avatar was to see it as a SL Me (a version of me) (e.g., R19, R54, R64) or Me in SL (myself being in SL) (e.g., R65, R66, R28). One respondent indicated, however, that he had created a very different type of avatar than he was himself and anticipated spending happy time "as we travel SL together" (R6) suggesting of a friendship rather than self-identification with an avatar.

The relational dimension was expressed also by an attachment to the environment. The respondent R48 described negative experiences about a "feeling that I should keep going back into [S]econd [L]ife even though I have some real life stuff to do. I don't like feeling obliged to go back in world". In contrast to the high levels of attachment, some respondents described their sense of aimlessness (e.g., R56) and addictiveness (1) of the environment. The most of the negative experiences were not related to the environment, but to the unpleasant behaviour of other residents. Griefing (SL term for intimidation) or bullying (13 responses), relationships with suspicious motives (6 responses), violence or aggression (5 responses) and other forms of perceived disrespect or misbehaviour were frequently mentioned (see Table 1). One informant described also how RL stigma (R28) had affected her online socialisation in SL.

Even if many of the informants emphasised the distinctness of SL environment, some respondents noted that the evolution of the relational dimension of social capital has influenced the formation of their social capital in RL. "I have found that, while I have always been curious about others in Real Life, I now have the courage and confidence to strike 
up a conversation with those that are VERY different from me... I'm more trusting in real life that these "unique" individuals will not harm me and will talk with me!" (R28).

Besides identity and identification, the relational dimension has also an informational focus. The respondents recorded best practices and learning outcomes (e.g., R5, R45) but also learning as an activity with an intrinsic value as positive experiences of their participation in SL (e.g., R2, R38, R65, R66). Learning outcomes and learning pertain to the mastering of both SL specific skills (e.g., use of SL for R53, R2; sword play in SL for R38) and learning in the broader context of everyday life (e.g., R38, R66). In the relational dimension of social capital in SL the negative (37) responses outnumbered the positive (29) ones, mainly due to the frequent occurrence of "humanities bad side also in SL", as one respondent puts it. The analysis also revealed that by far the most responses (66 compared to 33 in the structural dimension and 32 in the content dimension, see Table 1), as well as the most lengthy - and quite naturally most emotional - comments, were to be found in the relational dimension.

The content dimension of social capital is present in the outcomes of socialising and interactions in SL. The respondents describe several typical aspects of the content dimension in their responses: common experiences, shared goals, distinctive language and information exchange. The recurrence of common themes in the responses and accounts of how people work together (e.g., R28) and help each other to learn and use SL (e.g., R62, R64) indicate of the prevalence of common experiences and shared goals (6 responses pointed e.g. out "same goals" in a CoP context). Educational outcomes were mentioned frequently ( 8 responses on research/testing/learning, 3 specifically on learning outcomes and 2 on education/teaching, see Table 1). The development of SL specific language is apparent in how the residents (a SL term itself) use terms such as SL (for SL, e.g., "My first land deal in SL [..]" (R8]), RL (Real life, e.g., "RL stigma associated with [..]" (R28)) or griefing (annoying behaviour, e.g. "I have seen various issues of griefing [..]" (R15)). There are mechanisms and norms for behaviour regulation although this emerged as a somewhat problematic area, because there is a lot of evidence of clashes between expected RL and encountered SL behaviour. Conflicts can be managed inworld by filing reports, barring people from areas and by direct community action.

The responses contain also a wealth of evidence of multimodal exchange of information. Multimodality pertains to the variety of emotional, verbal and material modes of exchange as well as to the convergence of SL and RL information exchange (R3). Residents help each other to solve problems about SL in SL (R2) and help their SL friends in RL (R22). Respondents describe how they have asked for help and answered questions, exchanged ideas (R27) had "clever conversations" (R48), learned (e.g., R2, R5, R38), were able to test and do research (R4, R77) and, for instance, improved their social skills (R72). The reports of abuse or scam to Linden Lab are also a form of socially regulated information exchange in SL (e.g., R64, R77).

In the context of SL, it is also apparent that such modes of socialisation as fighting (R78), dancing (e.g., R12, R53), ice-skating and sword fighting (R38), romance (R2), sex (as a "provocative and stimulating" experience, R9), experiencing (R40) or "interacting" with a site (R27), excitement (e.g., R20) creating things for others (R33) and purchasing and exchanging virtual objects (e.g., R56, R65) represent forms emotional and (digitally) material information exchange. The same point of view is applicable to RL contexts, but in the context of SL, the informational underpinnings of all interactions (whether, for instance, emotional or commodity related) are accentuated by the very explicit mediatedness of the shared context of socialisation. Besides functioning as direct forms of information exchange, the respondents described also how, for instance, dancing, facilitated communication and information exchange in comparison to a conventional meeting (R12). In spite of the prevalence of negative social encounters, only two respondents described negative outcomes of their use of SL. One respondent described her frustration to SL (R38) and another one complained of the loss of time (R5). On the other hand, in no fewer than 30 responses were several positive, mostly educational, outcomes emphasized (see Table 1).

\section{Discussion}

There are some apparent limitations with the present study. The empirical material is a relatively small convenience sample that does not allow us to make broad generalisations. The general remarks of the (online) survey method (including measurement errors) [72], the retrospective and snapshot-like nature of the collected data, and quantitative versus qualitative approaches apply to this study. Instead of focusing on depth, the survey results aim at mapping broad patterns that can be elaborated further in future qualitative and quantitative studies. The survey was focused at the present even if it apparent, as one of the informants specifically commented (R18), that the temporal dimension and changes are highly significant in the emergence of social capital. In spite of limitations, the research data provides a rich material for the analysis of the dimensions of social capital and the relation of social capital and information sharing in SL and a useful addition to the relatively large corpus of qualitative studies. 
The analysis shows that SL is a rich environment for social and informational exchange with diverse outcomes. Emotion communication [35] may be seen as a partial informational and social outcome of the exchange per se, but the prevalence of emotional cues in the responses suggest of the significance of the role of emotions in information sharing and use in SL. Huvila et al. [3] made similar observation of the significance of "fun" as a form of knowledge exchange in a study of Google Lively. The implicit and explicit comparisons to RL encounters were often accompanied by adjectives like "exciting" (R20, R23), "fun and interesting" (R12) or "provocative and stimulating" (R9). In spite of the generally positive emotions, social and informational exchange in SL could also be, for instance, "annoying" (R9). A part of the emotional interestingness of the environment is obviously related to the experience of surprise and the "gamut" (R40) of people and places. The technology of SL was an especially typical source of negative emotions, or in terms of Mentis [51], device-induced frustration. Another negative outcome briefly discussed, for instance by Boellstorf [1, 126-127], quitting SL, was absent from the present material.

In spite of its richness, the present material does not provide definite answers to the question of the specific reasons for the accentuated role of emotional communication in SL. However, it complements earlier studies based on qualitative data gathering methods by presenting an overview of a larger population within which quantitative differences in the patterns of social capital have been observed in an earlier study [3]. Future studies with larger representative populations and qualitative research with a focus on specific populations and, for instance, contextual and longitudinal aspects of information sharing interactions are needed to provide additional evidence. Methodologically, it would be advisable to use a breadth of relevant retrospective and prospective research methods and approaches including large-scale surveys of representative populations of the residents of different virtual worlds, analyses of the records of actual written and oral communication, and, for instance, indepth ethnographic studies of social and informational practices to capture not only the premises but also the dynamics of these interactions. The alternation of interrelated positive and negative experiences of social exchange in SL may be seen as an indicator of the emerging nature of social and emotional intelligence in the context of SL. The most of the respondents describe highly positive and negative encounters with other people in SL. Whereas the environment was perceived by the majority of respondents to be aesthetically pleasing, it seems that in social exchange, a significant source of positive and negative experiences is a sense of surprise. The experience, negative or positive, had been completely opposite or radically different from the expected quality of the encounter. The observation seems to apply to both structural (e.g., dancing as a "more fun and interesting" (R12) form of social exchange) and relational aspects (serendipitous meeting of interesting people) of the encounters. The difficulties of being emotionally intelligent depend on the mediated nature of SL. The structural dimensions of SL give very different types of cues of emotional states and expectations than RL. At the same time, however, SL has distinct structural affordances (in Gibsonian [13] terms) that are helpful in developing a functioning zone of convergence for socialising. SL is a distinct, relatively neutral international 'place' that has apparently attracted people with similar interests and motives (as social software in general according to [32]) pertaining to such topics as education, learning, research, socialising and, for instance, sexual encounters even if sex is perceived as a controversial motive by the majority of the respondents. Similarly to the observations of Brooks and Nafukho [26], the present findings support the idea that emotional intelligence forms a basis for social capital, and the emotional intelligence related opportunities and constraints are directly related to its emergence.

In addition to the significance of possessing necessary emotional and cognitive skills [26,27], in SL, it seems to be important that an individual has developed a certain degree of practical mastery of the structure and emotional intelligence in the context of its relational affordances. They seem to function as a necessary prerequisite of being able to capitalise content (outcomes) from the social and informational exchange. SL still lacks some of the cues that make people aware of that what is familiar and non-familiar in the RL. SL has particular (digital) material and social affordances and constraints for social exchange [13], but the necessary social and emotional intelligence [25,26] for understanding the social milieu and developing trust within its confines are still evolving as suggested earlier by Füllbrunn et al. [31]. The analysis of the relational dimension of social capital showed the emergence of shared goals, common language and forms of expected behaviour, but in contrast to the World of Warcraft [24] and some other virtual communities [73], SL as a whole, has not turned (nor is there indications that it would be turning) to a community of strong rules and vigorous ritualistic behaviour even if such communities exist within its confines [74]. The relatively slow emergence of the relational opportunities of socialising is not surprising, as this has been shown to take time [16]. Similarly to the findings of Hall and Widén-Wulff [15], the occasional lack of trust seems to hamper information sharing in SL, too. Many respondents had negative experiences of encounters and communication with other avatars. People expect to get help from other avatars who are perhaps unwilling or unable to help (R68). People may experience that some avatars approach each other in too intimate ways (R28), are being "nasty" (R29), do not accept a no as an answer or have incompatible expectations of, for instance, the motives of inviting people to a bar (having a chat versus 
having a bar fight, R16). Even if many of these incidents may be seen as rather universally negative, it is clear that in several cases the participants have not been able to share information about their contexts and expectations. The outcome of the initially unpleasant bar fight, that a respondent became a good friend with his opponent suggest of the lack of a common frame of reference, but at the same time, of the possibility to overcome indifferences, create trust, obtain social capital and consequently, to share information.

Many residents use SL to keep in touch with their real life acquaintances and to meet people they would like to meet in real life (e.g., R14). Some people are trying to be as transparent as possible in SL about their real life identity (e.g., R17). In general, however, the attitude of many residents seems to be that RL and SL are two separate contexts and in the latter, the significant about you is your SL presence instead of that who you are in RL. As McKenna and Bargh [38] suggest of the Internet, SL, as a specific context within its confines, offers opportunities for trying new personality traits and provides a venue of expression, free of the social and emotional constraints of the physically based reality. At the same time, the prevalence of bullying and other forms of unwanted behaviour confirms earlier observations made in other types of virtual environments. The likelihood of anonymity as a significant reason for abusive behaviour $[35,41,42]$ is supported by the fact that the most of the bullies remain incognito.

In spite of the relative anonymity (or pseudonymity) of the residents, SL is not disconnected from the RL. Even if there is no correlation between the levels of social capital in SL and RL [3], its emergence in the two environments is influenced by the presence of the other. Residents have conflicting expectations of how to behave and what to expect of the others and their behaviour. As the description of how a respondent made her avatar more unattractive to avoid harassment shows, the behaviour in SL is linked to the cultural assumptions and behavioural patterns derived from the RL that are projected to the avatars' SL behaviour. This translation may cause negative emotional experiences and outcomes of social and informational exchange. When the emotional underpinnings of the social and informational exchange were reasonably balanced, the structural and relational dimensions of social capital contributed to the emergence of positive outcomes i.e. content. A respondent, who is atheist in RL, was happy to meet a foreign atheist in SL (R54). At the same time, SL seems to be capable of fostering an emergence of serendipitous communities of interest. People meet interesting people and get interested in variety of unfamiliar topics such as foreign politics or wine (R28). In spite of the variety of expressions of communality and otherness, SL is mostly interpreted as one 'place' instead of being a similarly heterogeneous context as the RL. For the most of the respondents, SL was a distinct "SL" (e.g., R14, $\mathrm{R} 17$, R54), rather than "a microcosm of all that is humanity and human experience, both good and bad" as one respondent (R56) put it. The paradox of the detachment of RL and SL and their simultaneous partial convergence is, as Barnes and Pressey [36] underline, the fact that the both evolve because the individual users are aiming to satisfy their perceived real world needs. As respondent R3 notes, "[i]t is not all about SL. RL sharing is important." The needs, whether related to sharing or to other aspects of the daily life, are not exclusive to RL or SL, but as the diversity of the outcomes of social exchange shows, they represent an amalgam of the both worlds. For some goals, SL can be instrumental, but as the responses demonstrate, learning and interacting in SL has become a real world goal for the respondents who described their positive experiences of learning to act in SL.

Besides the confluence of SL and RL goals, another point of convergence of the outcomes of social exchange in SL is their dual affinity to (non-instrumental) leisurely and (instrumental) work or serious leisure related activities. The positive emotional response of the experiences of being able to meet international colleagues, people who the respondents had heard of but never met, inspiration, learning about and through SL and the emergence of gradual albeit economically mostly insignificant earning of money signal of the possibility of a shift from leisurely to non-leisurely as Csikszentmihalyi [55] suggests. Instead of functioning as a purely leisurely or professional arena of informational exchange, SL functions as a convergent space that provides affordances for various degrees of the both. In this sense, SL seems to provide an interesting laboratory space for everyday life information research that would encompass both work and leisurely sides of our daily pursuits in the spirit of Goffman [75] rather than, for instance, Savolainen [76].

\section{Conclusions}

The central finding of the present study is the pertinence of emotional communication and information sharing in the emergence of social capital in SL, and consequently, the significance of emotional intelligence as a basis for successful social and informational exchange and vice versa. In spite of the lack of correlation between the level of social capital in SL and RL, its emergence in the virtual world is deeply affected by the dialectic of the conflicting expectations and experiences of the environment. The emergence of social capital in SL may be described as a process of accumulation of emotional intelligence that forms a basis for the exploitation of available structural and relational affordances of social and information exchange. Emotional intelligence is guiding ones actions and is therefore an important part and premise 
of a successful development of social capital. Looking into the emotional aspect brings additional insights to understanding the information practices that emerge in SL. Measuring the relationship between emotional intelligence, social capital, and information practices is a major challenge. However, an awareness of the mechanisms of the accumulation and functioning of social capital is an important accomplishment to start with that should be discussed in more detail that future qualitative and quantitative studies (based on relevant, both prospective and retrospective, approaches) of information sharing and its relation to emotions in the context of virtual worlds.

\section{Acknowledgements}

The authors would like to thank Dr. Kim Holmberg who conducted the data gathering together with the corresponding author and participated in discussing the aspects of social capital in Second Life in the early stages of this research.

\section{Funding}

This research received no specific grant from any funding agency in the public, commercial, or not-for-profit sectors.

\section{References}

[1] Boellstorff T. Coming of age in Second Life: an anthropologist explores the virtually human. Princeton: Princeton University Press; 2008.

[2] Malaby TM. Making virtual worlds: Linden Lab and Second Life. Ithaca: Cornell University Press; 2009.

[3] Huvila I, Holmberg K, Ek S, Widén-Wulff G. Social Capital in Second Life. Online Information Review. 2010;34(3):295-316.

[4] Minocha S, Reeves AJ. Design of learning spaces in 3D virtual worlds: an empirical investigation of Second Life. Learning, Media and Technology. 2010;35(2):111-137.

[5] Magerko B. The potential for scientific collaboration in virtual ecosystems. Learning, Media and Technology. 2010;35(2):243248.

[6] Peachey A. The Third Place in Second Life: Real Life Community in a Virtual World. Researching Learning in Virtual Worlds. 2010;p. 91-110.

[7] Ostrander M. Talking, looking, flying, searching: information seeking behaviour in Second Life. Library Hi Tech. 2008;26(4):512-524.

[8] Warburton S. Second Life in higher education: Assessing the potential for and the barriers to deploying virtual worlds in learning and teaching. British Journal of Educational Technology. 2009;40(3):414-426.

[9] Bourdieu P. La capital social. Actes de la Recherche en Sciences Sociales. 1980;(31):2-3.

[10] Putnam RD. The Prosperous Community: Social Capital and Public Life. American Prospect. 1993;(13):35-42.

[11] Nahapiet J, Ghoshal S. Social capital, intellectual capital, and the organizational advantage. Academy of Management Review. 1998;23(2):242-266.

[12] Widén-Wulff G, Ek S, Ginman M, Perttilä R, Södergård P, Tötterman AK. Information behaviour meets social capital: a conceptual model. Journal of Information Science. 2008;34(3):346-355.

[13] Gibson JJ. The perception of the visual world. Houghton Mifflin; 1979.

[14] de Souza Briggs X. Brown kids in white suburbs: Housing mobility and the many faces of social capital. Housing Policy Debate. 1998;9(1):177-221.

[15] Hall H, Widén-Wulff G. Social exchange, social capital and information sharing in online environments: lessons from three case studies. In: Huotari ML, Davenport E, editors. From information provision to knowledge production: Proceedings of the international conference for the celebration of the 20th anniversary of Information Studies, Faculty of Humanities, University of Oulu, Finland, June 23-25, 2008. vol. 8 of Studia Humaniora Ouluensia. Oulu: Oulu University Press; 2008. p. 73-86.

[16] Mayer RC, Davis JH, Schoorman FD. An Integrative Model of Organizational Trust. The Academy of Management Review. $1995 \mathrm{Jul} ; 20(3): 709-734$.

[17] Daniel B, Schwier RA, McCalla G. Social capital in virtual learning communities and distributed communities of practice. Canadian Journal of Learning and Technology. 2003;29(3):113-139.

[18] Södergård P. Virtuell gemenskap. Åbo Akademi University, Information Studies. Åbo; 2007.

[19] Ellison NB, Steinfield C, Lampe C. The Benefits of Facebook "Friends:" Social Capital and College Students' Use of Online Social Network Sites. Journal of Computer-Mediated Communication. 2007;12(4):1143-1168.

[20] Blanchard A, Horan T. Virtual communities and social capital. Social Science Computer Review. 1998;16(3):293-307.

[21] Putnam RD. Bowling alone. New York: Simon \& Schuster; 2000.

[22] Lin N. Building a Network Theory of Social Capital. Connections. 1999;22(1):28-51.

[23] Coleman JS. Social Capital in the Creation of Human Capital. The American Journal of Sociology. 1988;94:S95-S120.

[24] Williams D, Ducheneaut N, Xiong L, Zhang Y, Yee N, Nickell E. From Tree House to Barracks: The Social Life of Guilds in World of Warcraft. Games and Culture. 2006 October;1(4):338-361.

[25] Salovey P, Mayer JD. Emotional intelligence. Imagination, cognition, and personality. 1990;9(3):185-211. 
[26] Brooks K, Nafukho FM. Human resource development, social capital, emotional intelligence. Journal of European Industrial Training. 2006;30(2):117-128.

[27] Goyal A, Akhilesh KB. Interplay among innovativeness, cognitive intelligence, emotional intelligence and social capital of work teams. Team Performance Management. 2007;13(7/8):206-226.

[28] Riva G, Mantovani F, Capideville CS, Preziosa A, Morganti F, Villani D, et al. Affective Interactions Using Virtual Reality: The Link between Presence and Emotions. CyberPsychology \& Behavior. 2007;10(1):45-56.

[29] Jensen S. Actors and Their Use of Avatars as Personal Mediators: An empirical study of avatar-based sense-makings and communication practices in the virtual worlds of EverQuest and Second Life. MedieKultur Journal of media and communication research. 2009;25(47).

[30] Thomas D, Hollander JB. The city at play: Second Life and the virtual urban planning studio. Learning, Media and Technology. 2010;35(2):227-242.

[31] Füllbrunn S, Richwien K, Sadrieh A. Trust and Trustworthiness in Anonymous Virtual Worlds. Journal of Media Economics. 2011;24(1):48-63.

[32] Li DC. Online social network acceptance: a social perspective. Internet Research. 2011;21(5):562-580.

[33] Andrews DC. Audience-specific online community design. Commun ACM. 2002 Apr;45(4):64-68.

[34] Zhang Y, Hiltz SR. Factors that influence online relationship development in a knowledge sharing community. In: AMCIS 2003 Proceedings; 2003. p. 410-417.

[35] Derks D, Fischer AH, Bos AER. The role of emotion in computer-mediated communication: a review. Computers in Human Behavior. 2008;24:766-785.

[36] Barnes SJ, Pressey AD. Who needs cyberspace? Examining drivers of needs in Second Life. Internet Research. 2011;21(3):236-254.

[37] Webber S. Blended information behaviour in Second Life. Journal of Information Science. 2013;39(1):85-100.

[38] McKenna KYA, Bargh JA. Causes and consequences of social interaction on the Internet: a conceptual framework. Media Psychology. 1999;1:249-269.

[39] Wasko MM, Faraj S. Why Should I Share? Examining Social Capital and Knowledge Contribution in Electronic Networks of Practices. MIS Quarterly. 2005;29(1):35-57.

[40] Siegel J, Dubrovsky V, Kiesler S, McGuire TW. Group processes in computer-mediated communication. Organizational Behavior and Human Decision Processes. 1986;37(2):157 - 187.

[41] Daft RL, Lengel RH. Organizational information requirement, media richness and structural determinants. Management Science. 1986;32:554-571.

[42] McKenna KYA, Green AS, Gleason MEJ. Relationship formation on the Internet: what's the big attraction? Journal of Social Issues. 2002;58(1):9-31.

[43] Baumeister RF, Vohs KD, Nathan DeWall C, Zhang L. How Emotion Shapes Behavior: Feedback, Anticipation, and Reflection, Rather Than Direct Causation. Personality and Social Psychology Review. 2007;11(2):167-203.

[44] Russell JA. Core affect and the psychological construction of emotion. Psychological review. 2003;110(1):145.

[45] Kuhlthau CC. Inside the search process: Information seeking from the user's perspective. JASIS. 1991;42(5):361-371.

[46] Kuhlthau CC. Seeking Meaning: A Process Approach to Library and Information Services. Westport, CT: Libraries Unlimited; 2004.

[47] Kuhlthau CC. From Information to Meaning: Confronting Challenges of the Twenty-first Century. Libri. 2008;58(2):66-73.

[48] Heinström J. Fast surfers, Broad scanners and Deep divers - personality and information-seeking behaviours. Information Studies, Åbo Akademi University. Åbo; 2002.

[49] Heinström J. From fear to flow: personality and information interaction. Oxford: Chandos; 2010.

[50] Nahl D, Bilal D, editors. Information and emotion: The emergent Affective Paradigm in Information Behavior Research and Theory. Medford, NJ: Information Today; 2007.

[51] Mentis HM. Memory of frustrating experience. In: Nahl D, Bilal D, editors. Information and emotion: the emergent affective paradigm in information behavior research and theory. Medford, NJ: Information Today; 2007. p. 197-210.

[52] Nahl D. Affective load and engagement in Second Life: Experiencing urgent, persistent, and long-term information needs. International journal of virtual and personal learning environments. 2010;1(3):1-16.

[53] Cote D, Kraemer B, Nahl D, Ashford R. Academic librarians in Second Life. Library Innovation. 2012;3(1):20-47.

[54] Hartel J. Time as a framework for information science: insights from the hobby of gourmet cooking. In: Information Research 15 (4). Special Supplement: Proceedings of the Seventh International Conference on Conceptions of Library and Information Science - Unity in diversity - Part 2; 2010..

[55] Csikszentmihalyi M. Leisure and socialization. Social forces. 1981;60(2):332-340.

[56] Jahoda M. Work, employment, and unemployment: Values, theories, and approaches in social research. American Psychologist. 1981;36(2):184.

[57] Jahoda M. Employment and unemployment: A social-psychological analysis. Cambridge: Cambridge University Press; 1982.

[58] Ball M, Orford J. Meaningful patterns of activity amongst the long-term inner city unemployed: a qualitative study. J Community Appl Soc Psychol. 2002;12(6):377-396. 
[59] Mon L. Questions and Answers in a Virtual World: Educators and Librarians as Information Providers in Second Life. Journal of Virtual Worlds Research. 2009;2(1).

[60] Webber S, Nahl D. Sustaining learning for LIS through use of a virtual world. IFLA Journal. 2011;37(1):5-15.

[61] Ellis D. A behavioural approach to information retrieval system design. Journal of Documentation. 1989;45(3):171-212.

[62] Erdelez S. Information encountering. In: Fisher KE, Erdelez S, McKechnie LEF, editors. Theories of Information Behavior. Medford, NJ: Information Today; 2005. p. 179-184.

[63] Bullen P, Onyx J. Measuring Social Capital in Five Communities in NSW - A Practitioner's Guide. Coogee: Management Alternatives; 1998.

[64] de Nood D, Attema J. Second Life: The Second Life of Virtual Reality. The Hague: EPN; 2006. Available at http://www.epn.net/interrealiteit/Second_Life-Het_Tweede_Leven_van_Virtual_Reality.pdf.

[65] NMC, EDUCAUSE. The Horizon Report 2007 Edition. Austin: New Media Consortium and EDUCAUSE Learning Initiative; 2007.

[66] Holmberg K, Huvila I. The Second Life of Library and Information Science Education: Learning Together Apart. In: ASIST 2007 Proceedings of the 70th ASIS\&T Annual Meeting Joining Research and Practice: Social Computing and Information Science. vol. 44. ASIS\&T; 2007. p. 537-548.

[67] Holmberg K, Huvila I. Learning together apart: Distance education in a virtual world. First Monday. 2008 October;13(10).

[68] Jansen H. The Logic of Qualitative Survey Research and its Position in the Field of Social Research Methods. Forum Qualitative Sozialforschung / Forum: Qualitative Social Research. 2010;11(2).

[69] Glaser BG, Strauss AL. The discovery of grounded theory: Strategies for qualitative research. Hawthorne: Aldine; 1967.

[70] DuBois A. Close reading: an introduction. In: Lentricchia F, DuBois A, editors. Close reading: a reader. Durham, NC: Duke University Press; 2003. p. 1-40.

[71] Kidder LH. Qualitative research and quasi-experimental frameworks. In: Brewer MB, Collins BE, editors. Scientific inquiry and the social sciences. San Francisco: Jossey-Bass; 1981. p. 226-256.

[72] Tourangeau CFGCM Roger. The science of web surveys. Oxford; New York: Oxford University Press; 2013.

[73] Beekhuyzen J, von Hellens L, Nielsen S. Underground online music communities: exploring rules for membership. Online Information Review. 2011;35(5):699-715.

[74] Sixma T. The Gorean Community in Second Life: Rules of Sexual Inspired Role-Play. Journal ofVirtual Worlds Research. $2009 ; 1(3)$.

[75] Goffman E. The Presentation of Self in Everyday Life. Edinburgh: University of Edinburgh; 1956.

[76] Savolainen R. Everyday information practices: a social phenomenological perspective. Lanham: Scarecrow Press; 2008. 